\title{
К СТРУКТУРНО-МОРФОЛОГИЧЕСКОЙ ХАРАКТЕРИСТИКЕ ТОНКОЙ ФРАКЦИИ ОЗЕРНО-ЛЕДНИКОВЫХ ГЛИН ЮЖНОЙ ЭСТОНИИ
}

Минеральный состав тонкодисперсной фракции верхневалдайских озерно-ледниковых глин Южной Эстонии характеризуется многими компонентами. По данным рентгеноструктурного анализа, здесь преобладают гидрослюды с примесями каолинита и хлорита, а также присутствуют минералы с разбухающей решеткой как в виде различных смешанослойных образований, так и в виде монтмориллонита (Саарсе, Утсал, 1974). Наличием разбухающих образований озерно-ледниковые глины Южной Эстонии отличаются от глин более северных районов, для примесей которых более характерен каолинит (Пиррус, 1968). Причина такого различия не совсем ясна. Возможно, это обусловлено захватом в южноэстонские глины продуктов разрушения девонских пород, отдельные уровни которых содержат значительное количество смешанослойных минералов (Утсал, 1968). Однако не исключено, что здесь в какой-то мере сыграли роль различные гипергенно-постседиментационные условия, которые в хорошо дренируемых районах Южной Эстонии, несомненно, были иными, чем на севере республики.

Учитывая, насколько важны разбухающие минералы в формировании геотехнических свойств глинистых грунтов, нами было проведено электронно-микроскопическое изучечне озерно-ледниковых глин Южной Эстонии с целью получения дополнительной структурно-морфологической иформации о их тонкой фракции.

Исследования проводились в Институте экспериментальной биологии АН ЭССР под руководством А.-П. Сильвере на микроскопе «Тесла» BS-613. Был применен широко распространенный метод суспензии без привлечения химически активных диспергаторов (Викулова и др., 1957; Грицаенко и др., 1969). Исследованию подвергалась фракция менее 0,001 м⿻.

На всех полученных микроснимках отчетливо выделяются два типа тонкодисперсных глинистых частиц (табл. I, 1). Первые являются основными составляющими фракции - не менее $60-70 \%$ ее массы. Это сравнительно крупные (табл. I, 1-3), четко оконтуренные пластинчатые монозерна в основном неправильно-изометрической формы. При больших увеличениях (в 25000-32500 раз) на них нередко видно ступенчатое утончение пластины к краям - характерный признак минералов слюдистой группы. Псевдогексагональные очертания у них улавливаются очень редко, что не позволяет предполагать заметного количества среди них каолинита. Практически отсутствуют и вытянутые пластинки - показатели аутигенного происхождения этих частиц. Наоборот, 
многие крупные листочки имеют неправильно-оборванный контур или носят даже следы окатывания (табл. I, 3). Зерна с явными кристаллографическими очертаниями встречаются весьма редко (табл. II, 3), они являются, видимо, реликтами. Таким образом, все минералогические признаки однозначно свидетельствуют о том, что мы имеем дело с типичными гидрослюдистыми образованиями аллотигенного происхождения, что хорошо согласуется как с данными рентгеноструктурного анализа, так и с общими представлениями о генезисе озерно-ледниковых отложений.

Следует добавить, что в этом материале явно превалируют зерна с резкими, отчетливо выраженными краями. Расплывчатые контуры с хлопьевидно-агрегатными выделениями по краям зерен менее распространены, что, на наш взгляд, свидетельствует о незначительном изменении листочков гидрослюд в самом осадке. Наличие отдельных таких зерен скорее всего объясняется тем, что исходный материал, попадавший в глину, был изменен неравномерно.

Гораздо сложнее интерпретировать состав и генезис глинистых частиц второго типа, которые образуют мелкозернистый фон между крупными листочками гидрослюд. Они встречаются как в виде небольших $(0,2-0,5$ мк) дискретных частиц, так и в виде сложных чешуйчатых агрегатов (табл. I, 3; табл. II, 1, 2). В общей массе агрегатов больше, чем моночастиц. Формы дискретных частиц весьма разнообразны, но преобладают и здесь пластинки неправильно-изометрического контура, у которых признаки сглаживания первичных очертаний выражены менее четко. Наоборот, у этих частиц нередко наблюдаются прямые ребра явные кристаллографические элементы ограничения (табл. II, 1). Однако такие края почти никогда не оконтуривают зерна со всех сторон, и поэтому отчетливые кристаллиты попадаются редко. Сравнительно много среди частиц этой размерности и удлиненных пластинок, иногда близких к игольчатым зернам, но количество их сильно меняется от одного местонахождения к другому.

Таким образом, фактор аутигенности у этих глинистых частиц проявляется в большей степени, чем у частиц крупного размера. Однако подчиненная роль хорошо ограненных кристаллитов в этом материале, а также в основном агрегатное сложение зерен этой размерности свидетельствуют о том, что они представлены главным образом гидрослюдистыми образованиями, имевшими агрегатное строение уже в исходном материале и диспергированными на отдельные монозерна лишь в ходе подготовки препаратов к электронно-микроскопическому исследованию.

Правда, встречаются агрегаты и с расплывчатым контуром, обусловливающим постепенное снижение электронно-оптической плотности по краям частиц. Это, как известно, характерный признак присутствия монтмориллонита или других разбухающих фаз глинистых минералов (3хус, 1966; Beutelspacher, Van der Marel, 1968). Поскольку наибольшее количество таких агрегатов содержат как раз те образцы, в кото-

\section{ТАБЛИЦА I}

1 - Глинистые частицы $<0,001$ мм. Крупные, четко оконтуренные листочки гидрослюд неправильной формы и чешуйчатые агрегаты с менее четкими очертаниями частиц (гидрослюды, смешанослойные минералы, монтмориллонит). Местонахождение Луха. 2 Глннистые частицы двух типов: сглаженные крупные листочки слюды и разнотипные частицы агрегатного сложения, Местонахождение Каммери, 3 - Крупные листочки слюд округлого контура и мелкие листочки удлиненной формы. Местонахождение Тснргулинна. Увел, на всех снимках $10000 \times$. 

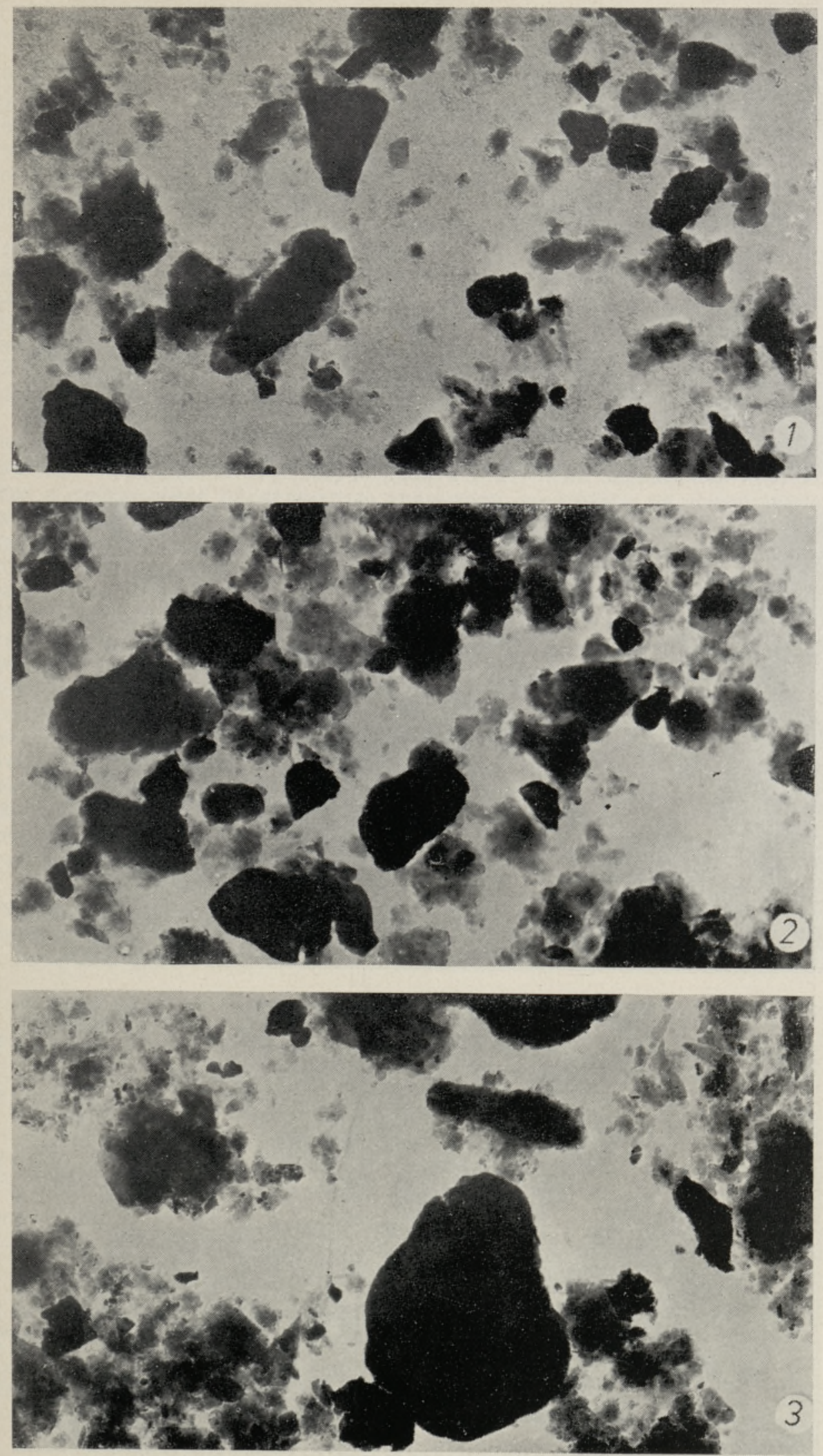

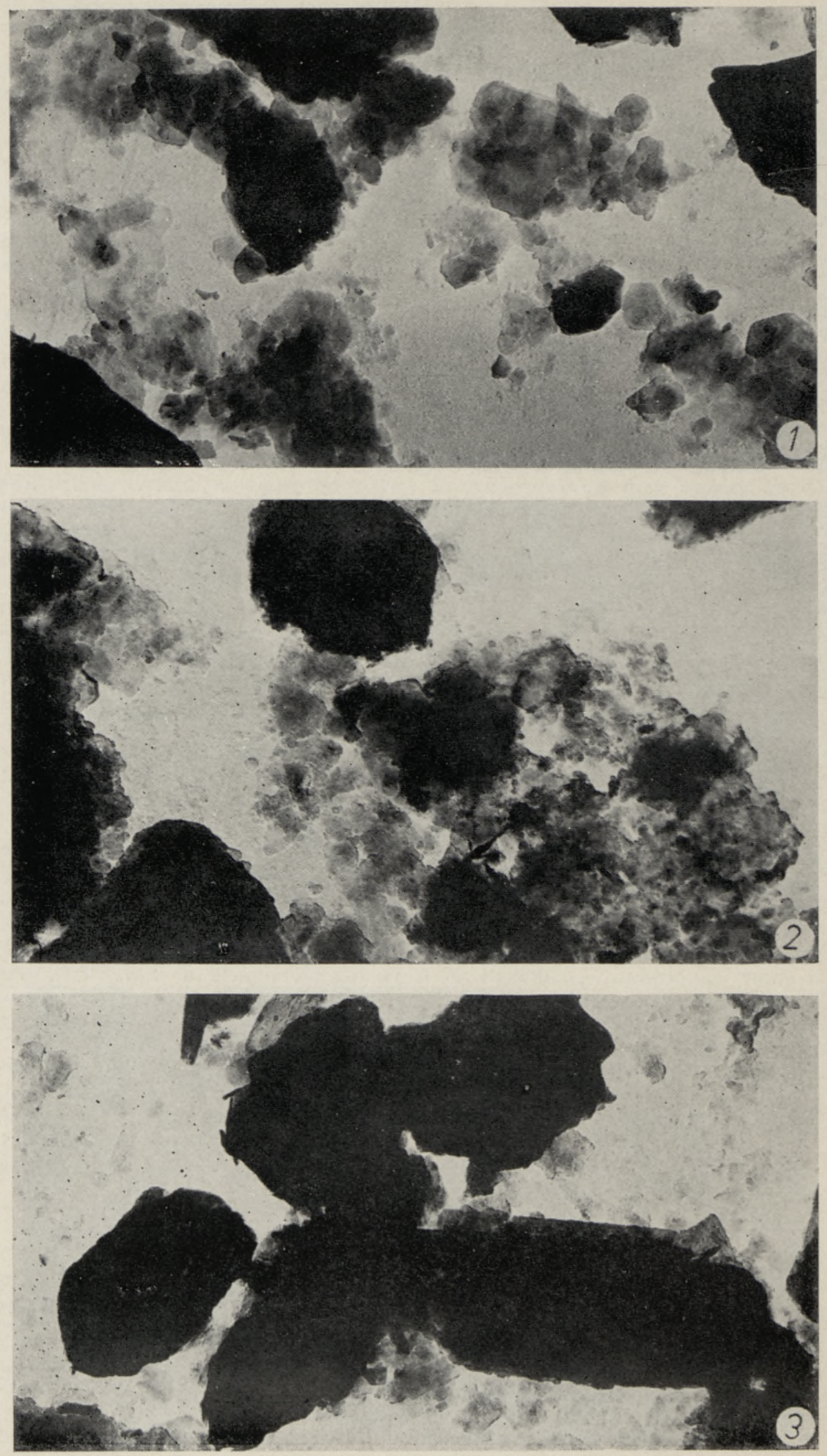
рых эти фазы установлены и рентгеноструктурным анализом, то идентификация их как монтмориллонитсодержащих образований вполне достоверна. При большом увеличении многие из этих агрегатов обнаруживают тонкопластинчатое строение (смешанослойные гидрослюда-монтмориллониты), а некоторые из-за расплывчатого контура сливаются с фоном препарата (монтмориллонит).

Таким образом, результаты электронно-микроскопического исследования полностью подтверждают данные рентгеноструктурной идентификации глинистых минералов и показывают, кроме того, надежность количественной оценки их состава по примененной нами методике рентгеноструктурного анализа. Электронно-микроскопическими снимками подтверждается также незначительная роль в этих глинах каолинита. К сожалению, нам не удалось выявить вермикулитовые образования, на присутствие которых указывали рентгеноструктурные исследования.

Полученный материал говорит также о незначительной роли аутигенеза в глинистой фракции изученных глин: сосредоточие частиц с различной минеральной характеристикой в отдельных зернах или агрегатах с соизмеримой размерностью указывает, во-первых, на поступление в бассейн весьма разнотипного материала и, во-вторых, на отсутствие процессов гомогенизации глинистых частиц в постседиментационную стадию. Это позволяет сделать важный практический вывод: поскольку глинистые минералы с разбухающей решеткой представлены в общем гидрослюдистом скелете осадка в виде отдельных механически привнесенных агрегатов и не являются продуктом постседиментационного изменения и деградации гидрослюдистого основания фракции в целом, значит, они не могут оказывать существенного влияния на геотехнические свойства этих глин. Следовательно, особенности минерального состава тонкой фракции играли при формировании геотехнических свойств глин гораздо меньшую роль, чем условия их залегания и постседиментационное уплотнение. Полученные результаты электронно-микроскопического изучения хорошо обосновывают выводы, сделанные ранее при изучении инженерно-геологических свойств глин данного района (Саapce, 1976).

Авторы искренне благодарны сотрудникам Института экспериментальной биологии АН ЭССР А.-П. Сильвере и К. Тарасовой за оказанную помощь при выполнении настоящего исследования.

\section{ЛИ Т Е Р А Т У Р А}

В ик улов а М. Ф., З в ягин Б. Б., Ш а хо в а Р. А. 1957. Электронно-микроскопический анализ. В кн.: Методическое руководство по петрографо-минералогическому изучению глин. М., с. 146-169.

Грицае н коГ. С., З вягин Б. Б., Боя рская Р. В., Горшков А. И., С атоин Н. Д., Фролов а К. Е. 1969. Методы электронной микроскопии минералов. M., $311 \mathrm{c}$.

3 х у с И. Д. 1966. Глинистые минералы и их палеогеографическое значение. М., 279 с.

Пи р р с $Э$ Э. А. 1968. Ленточные глины Эстонии. Таллин, 145 с.

\section{ТАБЛИЦА II}

1 - Агрегатные частицы, состоящие из мелких пластинок с четкими кристаллографическими гранями на отдельных участках. Местонахождение Реммески. Увел. 25000 ×. 2 - Aгрегаты сложного колломорфного (?) строения и расплывчатого контура. Представлены, очевидно, минералами с разбухающей решеткой. Местонахождение Юузамяги. Увел. $32500 \times .3-\mathrm{y}$ крупных листочков гидрослюд четкие кристаллографические элементы обнаруживаются редко. Местонахождение Кыверъярв, Увел. $32500 \times$. 
С а а р се Л., Утсал К, 1974. Рентгеноструктурная характеристика озерно-ледниковых глин Южной Эстонии, Изв. АН ЭССР, Хим. Геол., 23, 244-253.

$\mathrm{C}$ a а р се Л. 1976. Состав и геотехнические свойства отдельных типов озерно-ледниковых глинистых отложений Южной Эстонии. Изв. АН ЭССР, Хим. Геол., 25, $46-52$

Утсал К. 1968. О рентгенографическом исследовании глинистых минералов среднедевонских отложений Әстонии. Уч. зап. Тартуск. гос. ун-та, вып. 221. Тр. по геол., V. $3-29$.

Beutelspacher, H., Van der Mare 1, H. W., 1968. Atlas of electron microscopy of clay minerals and their admixtures. Amsterdam, $333 \mathrm{p}$.

$\begin{array}{cc}\text { Институт геологии } & \text { Поступила в редакцию } \\ \text { Академии наук Эстонской ССР } & 22 / \text { III } 1977\end{array}$

E. PIRRUS, Leili SAARSE

\section{LOUUNA-EESTI JÄÄJĂRVESAVIDE PEENE FRAKTSIOONI STRUKTUURILIS-MORFOLOOGILISTEST ISEÄRASUSTEST}

Lõuna-Eesti jääjärvesavide elektronmikroskoopilise uurimise pōhjal on eristatavad kaht tüüpi savimineraalid: tumedad, valdavalt isomeetrilise kujuga hüdrovilguterad ja heledamad, mitmesuguse kuju ja koostisega savimineraalide agregaadid. Osal viimastest on ebateravad ja elektronoptiliselt üleminekulised kontuurid, mistōttu neid võib vaadelda röntgenanalüüsil tuvastatud segakihtsete savimineraalide vői montmorilloniidina. Niisuguste agregaatide hajus paiknemine üldises hüdrovilkude pōhimassis viitab nende osakeste allotigeensele päritolule. Hajutatuse tõttu ei saa segakihtsed savimineraalid oluliselt môjustada uuritud pinnaste ehitusomadusi, mis sōltuvad eelkõige lasundite paiknemisest nüüdisreljeefis ja sellest tulenevaist settimisjärgseist tihenemisprotsessidest. Elektronmikroskoopilisel uurimisel saadud andmed on heas kooskōlas röntgenanalüüsi tulemustega, eriti savimineraalide hulga hindamise osas.

\section{TEXTURAL-MORPHOLOGICAL CHARACTERIZATION OF SOUTH ESTONIAN LIMNOGLACIAL CLAYEY DEPOSITS}

The paper presents the results of the textural-morphological investigation of clayey deposits from South Estonia. On the electron micrographs (Tables I, II) we can distinguish two types of clay minerals: particles of hydromica with irregular, angular borders and a plate-shaped or lath-like form, and interstratified minerals, assembled in aggregates. On the basis of the textural-morphological features and the scattered location in the general skeleton of hydromicas, the allotigeneous origin of the interstratified minerals has been proved. Due to it, the interstratified minerals have a relatively small influence on the formation of the geotechnical properties of these clays. The electron microscopical study is in good accordance with the results of X-ray determinations; by the way, they showed the correctness of the quantitative determination of different clay minerals by the mentioned method. 